\title{
The balance of power
}

\author{
Britain's energy supply is undergoing a revolution; for the first time since 1880, electricity production \\ was coal-free for 24 hours.
}

Changes are afoot in Britain's energy scene. An industry once reliant on coal is now dominated by an ever-increasing share of cleaner alternative sources: gas, nuclear, and renewables. The beginning of the end can be traced back to the 1990 s, when the so-called 'dash for gas' resulted in an explosion of gas-derived energy. Political obligations to meet Britain's climate change commitments, coupled with economic factors, have further shifted the balance of power from coal to alternative energy. The numbers speak for themselves: the Digest of UK Energy Statistics (DUKES; http:// go.nature.com/2q80ve7) reports that from 2014 to 2016, the share of coal in the power mix reduced from $29 \%$ to $9 \%$, while gas increased from $30 \%$ to $42 \%$, renewables (mainly wind) from $19 \%$ to $24 \%$, and nuclear remained fairly constant at $\sim 19 \%$.

With the importance of coal dwindling, 2016 saw a number of instances in which this carbon-intensive fossil fuel was not used to power the grid, but these were of relatively short duration. Until recently, the longest uninterrupted coal-free period was 19 hours in May 2016. However, a milestone in Britain's energy history was reached on 21 April 2017; this was the first continuous 24-hour period in which energy requirements were met without coal since 1882 , when the use of coal to generate power first began with the opening of the Holborn Viaduct power station in Battersea, London. Not only was this a first for Britain, but likely for any of the world's major economies.

As Britain moves towards a low-carbon economy, these coal-free periods can be expected to increase in duration and frequency. This comes amid governmental plans to close Britain's 8 remaining coalbased power plants by 2025, as well as increase investment in both gas-based stations and renewables. These proposed changes highlight Britain's desire to shift the balance of power away from coal, setting a precedent for other developed nations to follow suit. France and Canada both have similar plans to fully withdraw coal power by 2023 and 2030, respectively. Germany, where coal currently accounts for $\sim 40 \%$ of electricity generation, further aims to decarbonize coal power 'well before 2050'.

Although Britain is moving in the right direction, more needs to be done to make its energy supply sustainable. The shift from coal to gas is certainly advantageous in terms of curbing greenhouse gas emissions (coal emits twice as much $\mathrm{CO}_{2}$ as natural gas), but would greater investment in green energy be more fruitful in terms of finding a long-term solution and decreasing emissions? Plans are in place to increase financial support for offshore wind farms, but these are a long way off matching renewable investment and infrastructure in countries such as China and the United States, or the impressive renewable targets set by Sweden (the first $100 \%$-renewable country) and Denmark (fossil-fuel free by 2050). Nevertheless, coalderived energy in Britain has likely been consigned to history.

\section{Identifying authors}

\section{A requirement for unique author identifiers will enable clearer tracking of scientific contributions.}

In the coming weeks our readers may notice a change on our published Letters and Articles - starting from the end of April, Nature Climate Change now requires the corresponding author on these submissions to provide an Open Researcher and Contributor Identifier (ORCID) prior to acceptance. This unique digital identifier for each researcher allows attribution and clarity of authorship of any particular research output that it is added to. Contributing authors are also welcome to add ORCIDs but it is not a requirement of the mandate. It aims to simplify tracking and reporting of research output and on published versions of our accepted original research papers, it will appear next to the author name - on both print and online versions. Individuals follow a straightforward and free sign-up process to obtain an ORCID, which they then link to their profile on our online manuscript submission system. If the individual grants permission to CrossRef, together we will update your ORCID record at the time of publication, ensuring your publication is connected to your names and institution.

Nature Climate Change, along with thirteen other Nature Research titles, is participating in this mandate, which will be evaluated over a six-month period (http:// go.nature.com/2qbItHx). The requirement applies only for original research and is in line with implementation by a number of publishers across other publications (http:// go.nature.com/2qnbBvX).

This mandate for corresponding authors to provide an ORCID follows the recent announcement of the official signing up by Nature Research to the principles of the San Francisco Declaration on Research Assessment (DORA) (http://go.nature. com/2qIA81E). DORA aims to ensure that the scientific output of individuals and institutions is accurately measured and evaluated. Clarity in authorship helps to fulfil these ambitions.
It is not the only measure that is being undertaken to improve transparency in publication; in late 2016 we introduced the requirement for a data availability statement on all published primary research (http:// go.nature.com/2pOoA7R), following on from an earlier change in the way Methods were included in original research papers, allowing additional references and indexing of these. Plus in a move away from focusing on journal impact factors and in line with the DORA principles, additional journal metrics, both peer-review and citationbased, are now being provided for all of the Nature-branded journals, with more information available at http://go.nature. com/2arq70M.

We hope these changes to improve transparency and the new metrics information are useful and as with any new policy or trial we undertake, we are interested in hearing your thoughts and welcome your feedback. 